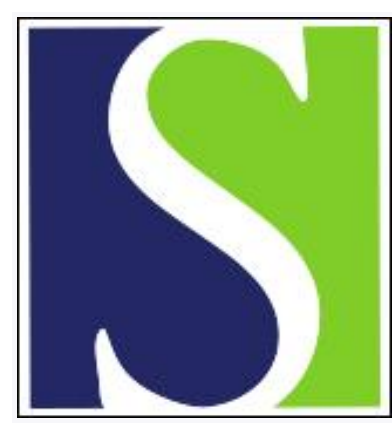

Scand J Work Environ Health 1988;14(2):118-124

https://doi.org/10.5271/sjweh.1946

Issue date: Apr 1988

Comparison between surgeons and general practitioners with respect to cardiovascular and psychosocial risk factors among physicians.

by Arnetz BB, Andreasson S, Strandberg M, Eneroth P, Kallner A

Affiliation: Harvard School of Public Health, Occupational Health Program, Boston, MA 02115.

This article in PubMed: www.ncbi.nlm.nih.gov/pubmed/3387959 


\title{
Comparison between surgeons and general practitioners with respect to cardiovascular and psychosocial risk factors among physicians
}

\author{
by Bengt B Arnetz, MD, PhD, MPH, ${ }^{1}$ Sven Andreasson, MD, ${ }^{2}$ May Strandberg, MD, ${ }^{3}$ \\ Peter Eneroth, MD, $\mathrm{PhD},{ }^{4}$ Anders Kallner, $\mathrm{MD}, \mathrm{PhD}^{5}$
}

\begin{abstract}
ARNETZ BB, ANDREASSON S, STRANDBERG M, ENEROTH P, KALLNER A. Comparison between surgeons and general practitioners with respect to cardiovascular and psychosocial risk factors among physicians. Scand J Work Environ Health 14 (1988) 118-124. The incidence of mortality from ischemic heart disease in Sweden has been reported to be elevated for surgeons in comparisons with most other groups of physicians. The objective of the present investigation was to compare cardiovascular risk factors and psychosocial work characteristics of surgeons and general practitioners, the latter having a substantially lower rate of ischemic heart disease. A random sample of 36 male surgeons and 30 male general practitioners was selected. The results showed no clear-cut differences in physiological risk factors. Overall mental strain was greater among the surgeons, as was the inability to relax after work, perceived work tempo, and total number of workhours. There were significant associations between psychosocial work characteristics and traditional cardiovascular risk factors, and the study gives further support to the validity of using long-term glucose markers, such as fructosamine, as indicators of metabolic stress.
\end{abstract}

Key terms: cholesterol, fructosamine, heart disease, stress.

Recent Finnish and Swedish data suggest that cardiovascular mortality among physicians is similar to that of other professions $(3,5,15)$. Within the medical profession in Sweden surgeons appear to be especially at risk to die from ischemic heart disease (incidence risk ratio $2.1,95 \%$ confidence interval $1.5-2.8$ ), according to rates for the period 1969-1983 (3). In the same study, general practitioners were found to be at low risk of death from ischemic heart disease. The finding that physicians do not seem to be better off than sociodemographically comparative groups has been suggested to be due to "either that doctors do not use their professional knowledge and skills in a way that lowers their own mortality or that other occupation-related factors cancel out any benefit [p 86]"' (15).

The purpose of the present study was to assess the distribution of cardiovascular and psychosocial risk factors among a group of randomly selected surgeons and general practitioners in an attempt to determine

1 Harvard School of Public Health, Occupational Health Program, Boston, Massachusetts, United States; National Institute for Psvchosocial Factors and Health, and Stress Laboratory, Karolinska Institute, Stockholm, Sweden.

2 Department of Social Medicine, Huddinge Hospital, Karolinska Institute, Stockholm, Sweden.

3 Occupational Health Clinic, Kopparbergs County Council, Falun, Sweden.

4 Division of Applied Biochemistry, Huddinge Hospital, Karolinska Institute, Stockholm, Sweden.

5 Department of Clinical Chemistry, Karolinska Hospital, Stockholm, Sweden.

Reprint requests to: Dr BB Arnetz, Occupational Health Program, Harvard School of Public Health, 665 Huntington Avenue, Boston, MA 02115, USA. whether there are any systematic differences in psychophysiological variables that could contribute to our understanding of why surgeons in Sweden are at increased risk to die from ischemic heart disease. We were also interested in comparing the work conditions of these two rather different groups.

\section{Subjects and methods}

A random sample of general surgeons and general practitioners was selected from a central register managed by the organization for pharmaceutical information (Läkemedelsstatistik AB). The organization has an up-to-date register of physicians residing in Sweden. From this list we selected 41 male general surgeons and 37 male general practitioners representing both metropolitan and rural areas.

The physicians were contacted by phone by one of three interviewers, who were also registered physicians. The potential participants were informed as to the background of the study, the content of the interviews, and the blood sampling procedure. The project had been approved by the Ethics Committee of the Karolinska Institute. Thirty-six surgeons and 30 general practitioners agreed to participate. There were no systematic differences between the participants and nonparticipants with regard to age, medical certification, or place of residence. The mean age was 46.8 (SD 7.9) years for the surgeons and 43.9 (SD 7.0) years for the general practitioners. The body mass index was 23.7 (SD 2.4) and 23.6 (SD 4.0), respectively.

The interviews were carried out in the physicians' offices, and a self-administered structured question- 
naire was used. The questionnaire covered the following areas: sociodemographics, marital status, professional title, work schedule, night calls, total number of years worked as a surgeon or general practitioner, smoking history, dietary and exercise habits, and average daily caffeine consumption. Work satisfaction, perceived work tempo, variation in work tasks, inability to relax after work, and mental and physical work load were assessed with a four- or fivepoint ordinal scale (likert-type) ranging from, for example, very low work tempo to very high work tempo. Moreover, three indices, based on a commonly used psychosocial work model, were compiled (16, 17). One index measured mental demands and consisted of five different items covering qualitative and quantitative mental work demands, such as a fast work pace and exposure to conflicting demands. The scores ranged from 5 to 20 . The second index measured intellectual discretion and consisted of four items regarding professional growth in one's job, monotony, and lack of task variation. The scores ranged from 4 to 16. Finally, the subject's perception of authority over decisions was measured on a two-item scale covering the ability to influence what and how things should be done. The scoring ranged from two to eight.

Systolic and diastolic blood pressure and heart rate were registered after the administration of the questionnaire. The body mass index [weight in kilograms/ (height in meters) ${ }^{2}$ ] was calculated for all the participants.

Blood samples were taken at the end of the interviews and analyzed for serum total cholesterol, highdensity lipoprotein (HDL) cholesterol, triglycerides, cortisol, dehydroepiandrosterone, vasopressin, insulin, fructosamine [a medium to fast indicator of blood glucose levels (12)], and gamma glutamyl transferase.
Standard laboratory techniques were used. Hormones were analyzed in duplicate with commercially available radioimmunoassays from Radioassay Systems Laboratories, Incorporated, Carson, California, and Immuno Nuclear Corporation, Stillwater, Minnesota, United States. Cross-reactions were checked and were found to agree with the information supplied by the manufacturers (4). The intra- and interassay coefficients of variation were below 10 and $20 \%$, respectively. We also calculated non-HDL cholesterol (defined as total cholesterol minus HDL cholesterol), low-density lipoprotein (LDL) cholesterol (defined as total cholesterol minus HDL cholesterol minus triglycerides divided by five), and the ratio of HDL to total cholesterol (8).

Student's t-test and Cochran-Mantel-Haenszel $(\mathrm{CMH})$ statistics were used to evaluate the differences between the surgeons and general practitioners. The participants were stratified on the basis of age (age $>45$ versus $\leq 45$ years) in the $\mathrm{CMH}$ analysis. Linear regression, using the method of least squares to fit the model, was applied to determine the associations between psychosocial and cardiovascular risk factors. Pearson product-moment correlation statistics were used. The significance level was set at $\mathrm{P}<0.05$.

\section{Results}

\section{Physiological and smoking data}

Table 1 depicts the results of the analysis of the physiological parameters. There were no statistically significant differences in the mean values between the two groups. In order to study possible differences in the distribution of the elevated levels of cardiovascular risk factors, we dichotomized values as elevated or not

Table 1. Averages and standard deviations of the physiological parameters for the surgeons and general practitioners. ( $\mathrm{HDL}=$ high-density lipoprotein, $\mathrm{LDL}=$ low-density lipoprotein)

\begin{tabular}{|c|c|c|c|c|c|c|}
\hline \multirow{2}{*}{ Parameter } & \multicolumn{3}{|c|}{ Surgeons } & \multicolumn{3}{|c|}{ General practitioners } \\
\hline & $\mathrm{N}$ & Mean & SD & $\mathrm{N}$ & Mean & SD \\
\hline Systolic blood pressure $(\mathrm{mmHg})^{a}$ & 36 & 132.7 & 20.2 & 30 & 132.8 & 15.1 \\
\hline Diastolic blood pressure $(\mathrm{mmHg})^{a}$ & 36 & 85.1 & 13.4 & 30 & 83.6 & 8.9 \\
\hline Serum cortisol (nmol/l) & 32 & 319.6 & 92.3 & 28 & 328.7 & 104.5 \\
\hline Serum thyroxin $(\mathrm{nmol} / \mathrm{l})$ & 32 & 104.5 & 21.0 & 28 & 110.5 & 13.2 \\
\hline Serum vasopressin (ng/ml) & 31 & 1.6 & 0.4 & 27 & 1.9 & 0.8 \\
\hline Serum insulin (mIU/l) & 30 & 7.6 & 4.0 & 27 & 7.9 & 5.8 \\
\hline Serum fructosamine $(\mathrm{mmol} / \mathrm{l})$ & 32 & 2.4 & 0.2 & 25 & 2.4 & 0.2 \\
\hline Serum gamma glutamyl transferase $(\mu k a t / l)$ & 33 & 0.5 & 0.3 & 27 & 0.5 & 0.1 \\
\hline \multicolumn{7}{|l|}{ Serum cholesterol ${ }^{b}$} \\
\hline Total cholesterol (mg/dl) & 34 & 229.4 & 43.0 & 28 & 228.4 & 39.7 \\
\hline Non-HDL cholesterol (mg/dl) & 34 & 170.7 & 46.2 & 28 & 169.2 & 37.7 \\
\hline LDL cholesterol (mg/dl) & 34 & 140.2 & 40.0 & 28 & 139.4 & 36.9 \\
\hline Triglycerides $(\mathrm{mg} / \mathrm{dl})^{\mathrm{c}}$ & 34 & 152.6 & 64.8 & 28 & 150.0 & 50.6 \\
\hline \multicolumn{7}{|l|}{ Cholesterol ratio } \\
\hline HDL to total & 34 & 0.26 & 0.08 & 28 & 0.26 & 0.06 \\
\hline $\mathrm{HDL}$ to $\mathrm{LDL}$ & 34 & 0.46 & 0.20 & 28 & 0.45 & 0.13 \\
\hline
\end{tabular}

a $1 \mathrm{mmHg} \approx 133.3 \mathrm{~Pa}$.

b $1 \mathrm{mg} / \mathrm{dl}=0.02586 \mathrm{mmol} / \mathrm{l}$.

c $1 \mathrm{mg} / \mathrm{dl}=0.0112 \mathrm{mmol} / \mathrm{l}$. 
elevated. CMH statistics were applied with stratification for age less than or equal to 45 years and older than 45 years (table 2). There were no statistically significant differences between the two groups with regard to the proportion of individuals exceeding the set cut-off points. Smoking habits, another established risk factor for ischemic heart disease, did not differ between the two groups. Fifteen subjects in each group had never smoked. Among the surgeons four smoked less than 10 cigarettes per day, three more than 10 , two smoked a pipe daily, and 12 had quit smoking completely. Among the general practitioners five smoked

Table 2. Cardiovascular risk factors according to the number of subjects exceeding the stated cut-off point. (OR = odds ratio, $95 \% \mathrm{Cl}=95 \%$ confidence interval)

\begin{tabular}{|c|c|c|c|c|c|}
\hline Risk factor & Surgeons & $\begin{array}{c}\text { General } \\
\text { practitioners }\end{array}$ & OR & $95 \% \mathrm{Cl}$ & P-value \\
\hline Total cholesterol $(>250 \mathrm{mg} / \mathrm{d} l)^{\mathrm{a}}$ & 8 & 6 & 1.0 & $0.3-3.7$ & 0.96 \\
\hline Triglycerides $(>200 \mathrm{mg} / \mathrm{dl})^{b}$ & 5 & 4 & 1.0 & $0.2-4.1$ & 0.97 \\
\hline Fructosamine $(>2.75 \mathrm{mmol} / \mathrm{l})$ & 4 & 0 & 2.8 & $0.3-29.3$ & 0.40 \\
\hline Systolic biood pressure $(>140 \mathrm{~mm} \mathrm{Hg})^{\mathrm{c}}$ & 8 & 5 & 1.4 & $0.4-4.8$ & 0.64 \\
\hline Diastolic blood pressure $(>90 \mathrm{mmHg})^{\mathrm{c}}$ & 7 & 5 & 1.2 & $0.3-4.3$ & 0.80 \\
\hline
\end{tabular}

a $1 \mathrm{mg} / \mathrm{dl}=0.02586 \mathrm{mmol} / \mathrm{l}$.

b $1 \mathrm{mg} / \mathrm{dl}=0.0112 \mathrm{mmol} / \mathrm{l}$.

c $1 \mathrm{mmHg}=133.3 \mathrm{~Pa}$.

Table 3. Psychosocial work characteristics according to the number of subjects exceeding the stated cut-off point. (OR $=$ odds ratio, $95 \% \mathrm{Cl}=$ confidence interval)

\begin{tabular}{|c|c|c|c|c|c|}
\hline Variable $^{\mathrm{a}}$ & Surgeons & $\begin{array}{c}\text { General } \\
\text { practitioners }\end{array}$ & OR & $95 \% \mathrm{Cl}$ & P-value \\
\hline Perceived work tempo (> 3) & 19 & 5 & 5.3 & $1.8-15.9$ & 0.003 \\
\hline Hectic work $(>2)$ & 12 & 4 & 3.3 & $0.8-14.0$ & 0.11 \\
\hline Inability to relax after work $(>3)$ & 25 & 13 & 2.7 & $1.0-6.8$ & 0.04 \\
\hline Inability to relax on weekends $(>3)$ & 10 & 2 & 5.4 & $1.0-38.8$ & $0.06^{\mathrm{b}}$ \\
\hline Psychologically taxing $(>2)$ & 29 & $2 \overline{3}$ & 1.2 & $0.4-3.8$ & 0.77 \\
\hline Physically taxing $(>2)$ & 32 & 7 & 35.6 & $10.1-125.8$ & 0.001 \\
\hline Too tired for friends $(>2)$ & 24 & 18 & 1.3 & $0.4-3.8$ & 0.57 \\
\hline Intellectual discretion $(>13)$ & 12 & 4 & 3.2 & $0.9-11.1$ & 0.07 \\
\hline Authority over decision $(>7)$ & 14 & 17 & 0.4 & $0.2-1.2$ & 0.10 \\
\hline \multicolumn{6}{|l|}{$\begin{array}{l}\text { Ratio index for mental demands } \\
\text { to authority over decisions and }\end{array}$} \\
\hline intellectual discretion $(>1)$ & 2 & 5 & 0.3 & $0.07-1.5$ & 0.15 \\
\hline
\end{tabular}

a Cut-off point operationally defined as having high strain in parentheses.

b Fisher's exact test $P=0.03$.

Table 4. Product-moment correlation coefficients between the psychosocial work characteristics and the physiological parameters.

\begin{tabular}{|c|c|c|c|c|c|c|c|c|c|}
\hline & $\begin{array}{l}\text { Body } \\
\text { mass }\end{array}$ & $\begin{array}{l}\text { Trigly- } \\
\text { cerides }\end{array}$ & $\begin{array}{l}\text { Non-HDL } \\
\text { cholesterol }\end{array}$ & $\begin{array}{l}\text { LDL } \\
\text { cholesterol }\end{array}$ & $\begin{array}{l}\text { Intellectual } \\
\text { discretion }\end{array}$ & $\begin{array}{l}\text { Authority } \\
\text { of decision }\end{array}$ & $\begin{array}{l}\text { Mental } \\
\text { demand }\end{array}$ & $\begin{array}{l}\text { Repetitive } \\
\text { work }\end{array}$ & $\begin{array}{l}\text { Weekly } \\
\text { work time }\end{array}$ \\
\hline Body mass & - & $0.46^{* * *}$ & $0.28^{*}$ & 0.16 & -0.23 & 0.20 & 0.15 & 0.24 & 0.15 \\
\hline Age & 0.23 & 0.08 & $0.27^{*}$ & $0.27^{\star}$ & 0.17 & $0.29^{*}$ & 0.10 & 0.03 & $0.30^{*}$ \\
\hline Total cholesterol & 0.12 & $0.29^{*}$ & $0.94^{\star * *}$ & $0.95^{* *}$ & -0.05 & $0.24^{\circ}$ & 0.12 & 0.11 & 0.003 \\
\hline $\begin{array}{l}\text { Intellectual } \\
\text { discretion }\end{array}$ & -0.23 & -0.14 & -0.06 & -0.02 & . & $0.26^{*}$ & -0.06 & $-0.58^{* *}$ & 0.14 \\
\hline $\begin{array}{l}\text { Authority of } \\
\text { decisions }\end{array}$ & 0.20 & 0.16 & $0.33^{* *}$ & $0.32^{*}$ & $0.26^{*}$ & . & -0.06 & $-0.28^{*}$ & -0.06 \\
\hline Mental demand & 0.15 & 0.03 & 0.10 & 0.07 & 0.09 & -0.06 & . & 0.16 & 0.22 \\
\hline Work tempo & -0.03 & 0.24 & 0.15 & 0.08 & 0.09 & -0.14 & $0.42^{*+*}$ & 0.04 & 0.23 \\
\hline Work satisfaction & -0.06 & -0.20 & -0.18 & -0.14 & $0.38^{* *}$ & $0.35^{\star *}$ & -0.03 & 0.10 & 0.08 \\
\hline $\begin{array}{l}\text { Systolic blood } \\
\text { pressure }\end{array}$ & $0.25^{*}$ & 0.19 & $0.30^{*}$ & $0.26^{*}$ & -0.07 & 0.07 & -0.05 & 0.19 & $0.29^{*}$ \\
\hline $\begin{array}{l}\text { Diastolic blood } \\
\text { pressure }\end{array}$ & $0.38^{* *}$ & 0.24 & $0.30^{*}$ & $0.26^{*}$ & -0.08 & $0.26^{*}$ & 0.07 & 0.17 & $0.34 * *$ \\
\hline Fructosamine & 0.001 & -0.05 & 0.13 & 0.16 & 0.06 & -0.04 & $0.36^{* *}$ & 0.20 & 0.01 \\
\hline
\end{tabular}


less than 10 cigarettes per day, three more than 10 cigarettes per day, none smoked a pipe, and seven had quit smoking completely $\left[\mathrm{X}^{2}\right.$ (4 degrees of freedom) $=2.9, \mathrm{P}=0.6]$.

\section{Psychosocial work characteristics, exercise habits and} sick leave

The psychosocial work characteristics for the two specialties are depicted in table 3 . The surgeons perceived themselves as having a higher degree of intellectual discretion, ie, a more stimulating job $(P<0.05)$. The surgeons worked an average of 47.1 (SD 9.2) h per week compared with 41.3 (SD 4.4) $\mathrm{h}$ for the general practitioners $(\mathrm{P}<0.01)$. The former group had an average of 17.8 (SD 26.4) h on night call per month, and the latter 13.0 (SD 17.4) $\mathrm{h}(\mathrm{P}=0.4)$. The surgeons had an average of 12 (SD 2.5) weeks of vacation and time-off due to accumulated overtime per year compared with 7.1 (SD 1.4) weeks for the general practitioners. Twenty-four surgeons versus seven of the general practitioners had not been on sick leave during the preceding year (odds ratio $6.5,95 \%$ confidence interval 2.2-18.9, $\mathrm{P}=0.001$ ). However, approximately $55 \%$ of the surgeons and $63 \%$ of the general practitioners stated that they had been sufficiently ill during the previous year to warrant sick leave if their work would have allowed them to stay home. A lack of personnel typically caused the doctors to go to work despite their suboptimal health.

Exercise habits did not differ between the two groups, 21 surgeons and 17 general practitioners exercising regularly (at least $1.5 \mathrm{~h}$ per week and/or two times or more). One out of three surgeons did not eat at regular times compared with one of the general practitioners $(P<0.0001)$. The consumption of coffee did not differ between the groups; the daily average consumption was 3.6 (SD 1.7) cups.

\section{Correlation between psychophysiological variables}

In order to assess the associations between various physiological and psychosocial work characteristics, product-moment correlation coefficients were calculated for some pertinent factors (table 4). Apart from what is shown in table 4 , systolic blood pressure was also associated with years of smoking [correlation coefficient $(\mathrm{r})=0.30 ; \mathrm{P}<0.05]$. The index of intellectual discretion was associated positively with the number of years worked within the specialty ( $\mathrm{r} 0.26$, $P<0.05$ ) and negatively with the number of days of sick leave $(r-0.30, P<0.05)$. The ratio of mental demand to intellectual discretion was associated with body mass ( $\mathrm{r} 0.33, \mathrm{P}<0.01$ ), demand ( $\mathrm{r} 0.76$, $\mathrm{P}<0.001)$, intellectual discretion $(\mathrm{r}-0.55, \mathrm{P}<$ 0.0001 ), work dissatisfaction ( $\mathrm{r} 0.29, \mathrm{P}<0.05$ ), number of days of sick leave ( $\mathrm{r} 0.32 ; \mathrm{P}<0.01$ ), and work tempo ( $\mathrm{r} 0.29, \mathrm{P}<0.05)$. The other psychosocial work characteristic index (ratio of mental demand to intellectual discretion and authority over decisions) was inversely related to work satisfaction $(r-0.37$, $P<0.01$ ), perception of work as being psychologically taxing ( $\mathrm{r} 0.44, \mathrm{P}<0.001$ ), number of days of sick leave (r $0.39, \mathrm{P}<0.01$ ), work tempo (r 0.34 , $P<0.01$ ), and perception of work as repetitious (r $0.43, \mathrm{P}<0.001$ ). Psychophysiologically, fructosamine was associated with mental demand and with the decision latitude indices. Authority over decisions was positively associated with diastolic blood pressure and total cholesterol level. Weekly workhours were positively associated with diastolic and systolic blood pressure and negatively with the dehydroepiandrosterone level $(\mathrm{r}-0.27, \mathrm{P}<0.05)$.

We fitted general linear models to assess the associations between specific psychosocial work characteristics and physiological parameters and to control for the effects of potential confounders (table 5). The fructosamine level continued to be positively associated

Table 5. General linear models for the psychosocial and physiological parameters. (LDL = low-density lipoprotein)

\begin{tabular}{|c|c|c|c|c|c|}
\hline $\begin{array}{l}\text { Dependent } \\
\text { parameter }\end{array}$ & $\begin{array}{l}\text { Independent } \\
\text { parameter }\end{array}$ & Estimate & $\mathrm{T}$ for $\mathrm{HO}$ & $\mathrm{pr}>\mathrm{T}$ & $\begin{array}{l}\text { Standard error } \\
\text { of the estimate }\end{array}$ \\
\hline \multirow[t]{2}{*}{ Body mass ${ }^{a}$} & \multirow{2}{*}{$\begin{array}{l}\text { Intercept } \\
\text { Age } \\
\text { Intellectual } \\
\text { discretion }\end{array}$} & $\begin{array}{r}24.92 \\
0.11\end{array}$ & $\begin{array}{l}7.39 \\
2.35\end{array}$ & $\begin{array}{l}0.0001 \\
0.02\end{array}$ & $\begin{array}{l}3.37 \\
0.05\end{array}$ \\
\hline & & -0.54 & -2.33 & 0.02 & 0.23 \\
\hline Fructosamine $^{\circ}$ & $\begin{array}{l}\text { Intercept } \\
\text { Mental demands }\end{array}$ & $\begin{array}{l}1.97 \\
0.03\end{array}$ & $\begin{array}{r}12.11 \\
2.85\end{array}$ & $\begin{array}{l}0.0001 \\
0.006\end{array}$ & $\begin{array}{l}0.16 \\
0.01\end{array}$ \\
\hline \multirow[t]{3}{*}{ Total cholesterol } & \multirow{3}{*}{$\begin{array}{l}\text { Intercept } \\
\text { Body mass } \\
\text { Triglycerides } \\
\text { LDL cholesterol } \\
\text { Authority of } \\
\text { decision } \\
\text { Years within the } \\
\text { same specialty }\end{array}$} & $\begin{array}{r}122.58 \\
-1.84 \\
.10 \\
1.02\end{array}$ & $\begin{array}{r}60.21 \\
6.70 \\
14.19 \\
599.21\end{array}$ & $\begin{array}{l}0.0001 \\
0.012 \\
0.0004 \\
0.0001\end{array}$ & $\begin{array}{r}15.80 \\
0.71 \\
0.02 \\
0.04\end{array}$ \\
\hline & & -2.11 & 4.51 & 0.038 & 0.99 \\
\hline & & 0.35 & 4.20 & 0.045 & 0.17 \\
\hline
\end{tabular}

a R-square for model $=0.13$.
b R-square for model $=0.13$.

c R-square for model $=0.93$. 
with mental work demand, but the total cholesterol level was inversely associated with authority over decisions. The serum cortisol level (natural logarithm) was associated with work satisfaction (R-square 0.10 , $P<0.05$ ). The psychosocial work indices did not contribute significantly to the best predictor model for diastolic and systolic blood pressure.

The surgeons stated that the four most positive aspects of their work were (i) that the work was stimulating and varied $(\mathrm{N}=15)$, (ii) that it offered patient contact $(\mathrm{N}=11)$, (iii) that it allowed one to work with interesting problems $(\mathrm{N}=6)$, and (iv) that one got to solve important problems $(\mathrm{N}=1)$. These same positive aspects were listed by the general practitioners $7,8,2$, and 4 times $(P<0.05)$, respectively. The surgeons rated time pressure $(N=13)$, lack of control over the work schedule and difficulties keeping up with medical progress $(\mathrm{N}=2)$, distorted views of what being a surgeon would really be like and that work interfered too much with social life $(\mathrm{N}=11)$, and waste of time on "meaningless" duties such as filling out medical evaluation forms $(\mathrm{N}=5)$ as negative aspects of being a surgeon. These same negative aspects were listed by the general practitioners $16,5,4$, and 1 times $(P<0.05)$, respectively.

\section{Discussion}

The present study was a pilot investigation of a small number of randomly selected general surgeons and general practitioners residing in Sweden. The purpose of the study was to assess whether work-related stress factors and specific physiological parameters would yield some clues as to why Swedish surgeons are at increased risk of dying from ischemic heart disease and why general practitioners are not at such risk (3). Moreover, we attempted to further our understanding of the psychophysiological factors that could be of importance in attempts to understand why physicians in general are at a similar risk to die from ischemic heart disease as the general population $(3,5,15)$. Although we selected a random sample, generalization to all physicians in these two groups should be done with great caution. This caution is necessary partly because of the myriad of possible confounders that are at work. Internal validity is likely to be high however. Selection bias was unlikely to have had any major effects since a large majority of the initially selected individuals consented to participate. Nevertheless, due to the aforementioned factors and the small sample size, replication of our findings is clearly needed.

There were no significant differences between the two groups in mean values of the selected physiological parameters. Compared to the originally screened population in the Helsinki Heart Study $(\mathrm{N}=18966)$, our values tended to be slightly lower for systolic and diastolic blood pressure and total cholesterol level, as well as for the measured subfractions of cholesterol
(8). The percentage of nonsmokers was similar. These results were also consistent with those of another Swedish study which showed no clear-cut differences for cholesterol and triglycerides among men who represented six widely different occupations, including physicians and cargo handlers (17). Moreover, the observed values were well within the center of the distribution of the reference curves in the hospital laboratory used for the analysis. Thus, our sample does not support the notion that physicians adopt a healthier life-style than other socioeconomically comparative groups. Moreover, regular exercise was no more common in our population than that found for professionals in general.

When predetermined cut-off points were used to define a person as belonging to a high-risk group for specific physiological parameters, no clear-cut differences emerged between the surgeons and general practitioners. The odds ratios for surgeons were elevated for fructosamine, but the $95 \%$ confidence intervals included 1 . The wide confidence bounds are partly due to the limited sample size, and it would be of value to assess cardiovascular risk factors in a larger sample. However, of the most consistently found risk factors for ischemic heart disease (smoking, age, blood pressure, and total cholesterol level) none differed significantly from unity $(1,6,7)$.

Major differences emerged between the two groups with regard to psychosocial work characteristics. Surgeons reported higher scoring on the scales measuring work tempo, hectic work, inability to relax after work, and perception of work as physically demanding. These characteristics are recognized jobrelated psychosocial stress factors. Although there is no unequivocal association between these factors and future risk to die from ischemic heart disease, sustained psychophysiological activation might possibly lead to adverse health effects over an extended period of time (1). Theorell et al reported an association for hectic work and failure to acquire new skills in one's profession with myocardial infarction $(16,17)$. In the present study surgeons actually reported that they felt that they learned new skills. However, long workhours, which was the most common for surgeons, are likely to put a person at increased risk (16). Despite the surgeons' high ratings on psychosocial work stressors, they did not differ significantly from the general practitioners on the decision latitude indices, which assessed the ratio between mental work demand and authority over decisions: Furthermore, the surgeons scored higher on the scale measuring intellectual discretion. They also stated more commonly than the general practitioners that work was stimulating and varied and that it implied working with interesting problems. On the negative side, both groups stated time pressure as the main factor. Although surgeons felt that their work had interfered too much with their social life, none regretted that they had entered the surgical profession. Some of these stressors have been reported for other 
health care personnel as well, and they are not unique for physicians (13).

Regression analysis, using specified physiological parameters as dependent variables, failed to include the medical discipline as a significant independent predictor. A number of psychosocial work characteristics entered the model however. Thus the ratio of mental demand to intellectual discretion was inversely related to body mass. Obesity has been reported to be an independent risk factor for ischemic heart disease, and its association with psychosocial work characteristics suggests intermediate pathways by which psychosocial factors might enhance a person's risk (10).

Mental work demand remained the most important predictor of fructosamine levels, even after the effects of serum insulin, age, and cholesterol were controlled for. This finding supports our previously presented hypothesis that hemoglobin $\mathrm{A}_{1 c}$ and fructosamine, both of which reflect integrated blood glucose values over a longer time period, might reflect overall metabolic stress levels in the body (4). Some studies have also implicated serum glucose levels as a cardiovascular risk factor, even though these studies need further follow-up (9). The serum cholesterol level was negatively associated with authority over decisions after body mass, triglycerides, and age were controlled for. This finding is consistent with epidemiologic data indicating enhanced ischemic heart disease risk among subjects with low decision latitude (16).

In conclusion, the present study could not substantiate any major differences in physiological risk factors between surgeons and general practitioners that would further our understanding of why surgeons are an apparent risk group for ischemic heart disease in Sweden. However, a number of psychosocial work characteristics differed between the groups. Overall psychological arousal was consistently higher among the surgeons. It is feasible to speculate that such psychosocial factors act independently of traditional risk factors and could contribute to the enhanced risk for surgeons. However more research is needed to substantiate such a hypothesis. The study further substantiates previous results indicating that the physiological risk-factor profile of physicians is no better than that observed for other professionals. One may wonder why it is that physicians do not adopt a healthier life-style in order to combat ischemic heart disease. It seems that knowledge alone is not sufficient; instead it must be linked with a certain amount of fear before it induces changes in life-style (11). This coupling might not exist among physicians, or, alternatively, their work conditions do not allow them sufficient opportunity to put this knowledge to use.

The differences between the groups with respect to sympathetic activity might have been better evaluated if the subjects had been studied under actual work conditions (14). It is possible that changes in highly labile endocrine systems are not reflected in basal measurements. However, a number of the traditional risk factors, such as blood lipids, are slow reactors that do not change substantially over a short period of time.

Compared with Swedish white-collar workers, the physicians studied appeared to enjoy their work to a greater extent, perceived it as more hectic and more psychologically demanding, and lacked control over everyday planning to a greater extent (2). However, they also reported that they developed and learned new skills to a greater extent in their profession.

In summary, a physician's work environment contains a number of severe stressors not commonly faced by personnel outside the health care sector, but the work also entails many rewarding and satisfying experiences. The physicians studied had a very strong feeling of responsibility towards their work and rarely stayed home when they were sick. A more-detailed analysis of the physicians' work environment is likely to give us a better understanding of factors that increase a worker's ability to cope and enjoy work despite occasional demanding circumstances.

\section{Acknowledgments}

This paper was made possible by grants from the Swedish Work Environment Fund (84-1013), the Swedish Society of Medicine (1985-36 \& 1986-19), SALUS' 50-year Fund, Nanna and Albert Skantze's Memorial Fund, and the Karolinska Institute's research funds. Dr BB Arnetz was supported in part by a postgraduate fellowship from the Swedish Work Environment Fund (86-0309) and by a National Research Service Award from the United States National Institute of Environmental Health Sciences (5-T32-ES-07069). We are greatly indebted to the participating physicians, who enthusiastically agreed to volunteer their time to be interviewed.

\section{References}

1. Arnetz BB. Interactions of biomedical and psychosocial factors in research on aging: A European perspective. In: Eisdorfer C, Lawton MP, Maddox GL, ed. Annual review of gerontology and geriatrics. Volume 5. Springer Publishing Company, New York, NY 1985, pp 56-94.

2. Arnetz BB, Andreasson S, Strandberg M, Eneroth P, Kallner A. Läkares psykosociala arbetsmiljö: Stress, hälsorisker - och trivsel [Physicians work environment: Stress, health hazards - and satisfaction]. Läkartidningen 84 (1987) 816-824.

3. Arnetz BB, Hörte L-G, Hedberg A, Theorell T, Allander E, Malker H. Läkares dödlighetsmönster i ischemisk hjärtsjukdom (IHD) och suicid - data baserade på dödsfallsregistret och socialstyrelsens läkarförteckning [Mortality pattern from ischemic heart disease and suicide: A cohort study]. Karolinska Institute, Stockholm 1986. 24 p. (Stressforskningsrapporter nr 185). (English summary).

4. Arnetz BB, Theorell $T$, Levi L, Kallner A, Eneroth P. An experimental study of social isolation of elderly people: Psychoendocrine and metabolic effects. Psychosom Med 45 (1983) 395-406. 
5. Asp S, Hernberg S, Collan Y. Mortality among Finnish doctors, 1953-1972. Scand J Soc Med 7 (1979) 55-62.

6. Brand RJ, Rosenman RH, Sholtz RI, Friedman M. Multivariate prediction of coronary heart disease in the Western collaborative group study compared to the findings of the Framingham study. Circulation 53 (1976) $348-355$.

7. Burch PRJ. Ischemic heart disease: Epidemiology, risk factors and cause. Cardiovase Res 14 (1980) 307-338.

8. Frick MH, Elo O, Haapa K, Heinonen OP, Heinsalmi $P$, Helo P, Huttunen JK, Kaitaniemi P, Koskinen P, Manninen V, Mäenpää $H$, Mälkönen $M$, Mänttäri $M$, Norola S, Pasternack A, Pikkarainen J, Romo M, Sjöblom T, Nikkilä EA. Helsinki heart study: Primaryprevention trial with gemfibrozil in middle-aged men with dyslipidemia: Safety of treatment, changes in risk factors, and incidence of coronary heart disease. N Engl J Med 317 (1987) 1237-1245.

9. Fuller JH, Shipley MJ, Rose G, Jarrett RJ, Keen H. Mortality from coronary heart disease and stroke in relation to degree of glycaemia: The Whitehall Study. Br Med J 287 (1983) 867-870.

10. Hubert H, Feinleib M, McNamara P, Castelli W. Obesity as an independent risk factor for cardiovascular disease: A 26-year follow-up of participants in the Framingham heart study. Circulation 67 (1983) 968977.

11. Job RFS. Effective and ineffective use of fear in health promotion campaigns. Am J Publ Health 78 (1988) $163-167$

12. Johnson RN, Metcalf PA, Baker JR. Fructosamine: A new approach to the estimation of serum glycosylprotein: An index of diabetic control. Clin Chim Acta 127 (1982) 87-95.

13. Leppänen RA, Olkinuora MA. Psychological stress experienced by health care personnel. Scand J Work Environ Health 13 (1987) $1-8$.

14. Payne RL, Rick JT, Smith GH, Cooper RG. Multiple indicators of stress in an 'active' job - Cardiothoracic surgery. J Occup Med 26 (1984) 805-808.

15. Rimpelä $\mathrm{AH}$, Nurminen $\mathrm{MM}$, Pulkkinen $\mathrm{PO}$, Rimpelä MK, Valkonen T. Mortality of doctors: Do doctors benefit from their medical knowledge? Lancet 1 (1987): $84-86$.

16. Theorell T. Stress at work and risk of myocardial infarction. Postgrad Med J 62 (1986) 791-795.

17. Theorell T, Ahlberg-Hulten G, Berggren T, Perski A, Sigala F, Svensson J, Wallin B-M. Arbetsmiljö, levnadsvanor och risk för hjärt-kärlsjukdom [Work environment, personal habits and heart disease risk]. Karolinska Institute, Stockholm 1987.80 p. (Stressforskningsrapporter nr 195). (English summary).

Received for publication: 10 August 1987 